\title{
On the Emergence of Firms and Sick Institutions
}

\section{Mahadea}

Department of Economics, University of Natal, Pietermaritzburg

\section{ABSTRACT}

Organisations and firms are formed by people and entrepreneurs. Firms can become sick just as people do. Not all firms live forever. This paper examines the emergence of "sick" institutions. Organisations can become unhealthy when there is a mismatch between goods and services they produce and the external environment in which they operate. Survival and fitness of an organisation depend on its ability to respond and adapt cost-effectively to the changing environment. Entrepreneurship, n-Achievement and productivity of individuals are critical to an organisation's health. A thorough diagnostic framework of symptoms of organisational ills is required before prescribing any therapy, to bring about a healthy organisation. The future belongs to healthy firms, with adaptable strategies and resources that optimally fit the changing environment.

JEL D 21

\section{INTRODUCTION}

Change is rapidly taking place in the domestic and the world economy. South Africa has been successful in its political transformation process. To a certain extent, the political change has a parallel process at an organisational level. In this high-tech era of globalisation, firms have to adapt fast to a changing environment if they are to remain competitive. Previously practised inwardlooking strategies may not work in the present situation. Many firms in South Africa and elsewhere are downsizing, re-engineering, retrenching, and adopting innovative strategies in response to changing economic, social, political and technological circumstances. On the other hand, these changes are providing scope for the birth of small entrepreneurial firms, although perhaps different from the transaction cost framework. At the same time, hazard rates among small firms are increasing. At a time when trade and tariff barriers are being dismantled globally, South African firms are being burdened with more levies, regulations, labour laws and trade union actions. All these drive up business costs, impact negatively on enterprise competitiveness, causing job losses and threatening the health of many firms. 
The changing environment poses formidable challenges to organisational leaders in their quest for the efficient production of goods and services. Clearly many of the old organisational constructs may become casualties of this change if they do not innovate or transform to meet the new economic order. Accordingly, entrepreneurs, managers and workers have to learn fast and implement new ways of doing things if their firms are to thrive on the challenges of tomorrow. Otherwise, firms are prone to organisational "sickness"; this is more likely if the firm's strategies and internal systems are not apt to meeting market needs in a cost-effective manner. Organisational sickness may be interpreted in diverse ways. A firm is often unhealthy because of unethical behaviour by the people working in it, due to weaknesses in the structures of the organisation, such as layers of management, decision-making procedures and control systems. However, for the purpose of this paper, an organisation is said to be "sick", when there is a mismatch between its internal system, or the goods and services it produces, and the broader environment in which it operates.

This paper presents a somewhat fragmented analysis of the emergence of firms and sick institutions. It consists of three parts; the first gives the theoretical approach underpinning the emergence of the firm and its organisational structure; the second examines some characteristics of sick organisations, and some "cures" are suggested in the third and last section.

\section{THE FIRM AND ITS EMERGENCE}

A firm may be considered a planning unit for the conversion of inputs into output of goods and services. In an organizational framework, the word "firm" is used broadly and includes more than just entities producing marketable goods and services. As social institutions, firms have evolved to take various forms; these include single traders, partnerships, companies, non-profit organisations, public sector services and non-government organisations (NGOs). The formation of a firm can be regarded as the gathering by the entrepreneur of signatures to an agreement binding members together by self-interest. The firm appears as a direct consequence of problem-solving activities by entrepreneurs (Casson, 1991).

Ronald Coase (1964: 339) defines the firm as "the system of relationships which comes into existence when the direction of resources is dependent on an entrepreneur". This system of relationships is based on the cooperation between factors of production and the contractual agent, the entrepreneur. Owners of resources co-operate within the firm through bilateral contracts between each resource owner and the contractual agent. The contracts are so framed as to 
reduce the transactions costs associated with exchange in the market (Ricketts, 1994: 72).

Extending the work of Coase, Williamson (1985) argues that institutions are the mechanisms which govern transactions, and a transaction occurs "when a good or service is transferred across a technologically separable interface" (1985: 1). According to North (1990a: 4) institutions are "a framework within which human interaction takes place". More specifically, "Institutions are the humanly devised constraints that structure human interaction" (North, 1994: 360). They encompass formal rules (legal and regulatory environment), informal constraints (norms of behaviour, conventions and codes of conduct) and their enforcement characteristics, that guide human behaviour. The firm is an institution because transactions between departments or people represent interaction across a separable interface.

Goal orientation is basic to all economic activities of the firm. According to the neoclassical view, the objective of the firm is to maximise profits. In the neoclassical framework, it is assumed that the firm operates in an environment of perfect competition, there is no transaction costs (implicitly zero) and no agency problem. Owners of the firm are assumed to possess perfect knowledge about prices and technologies, and all owners are fully competent in their pursuit of profit. Profits are the means of survival of the firm. The selection criteria of evolutionary processes may account for the survival of profitable firms and the failure of unprofitable ones (Demsetz, 1997: 67).

In the context of competitive equilibrium, an actual firm will be the efficient firm when it is operating at the minimum point of its average cost. Operating at a level below the minimum long run average cost implies that there are possibilities for reaping increasing returns to scale. Beyond the minimum efficient scale, costs tend to rise. If the firm does nothing about controlling its costs and monitoring its activities, then initial signs of inertia and sickness start developing within the organisation. On this view, costs are determined not purely by the nature of the production function or technology, but by the effectiveness of the firm in decision-making. Within the firm, resources move according to management direction and not necessarily in terms of price signals.

Lucas (1978) associates a firm with a manager, and posits decreasing effectiveness of management, as the scale of production is increased. In this institutional context, if there cannot be a replication of the entrepreneurial or managerial input, the quality of decision-making would suffer, and this can impact adversely on the overall health and functioning, as well as the size, of the organisation. Some of the organisational inputs are fixed, at least in the short term, especially entrepreneurial talents. In equilibrium, firms with 
superior talents will be larger than those with inferior ones. At individual enterprise level, the greater the talents of the entrepreneur, the greater is the size of the firm that he manages.

Organisational efficiency and efficient organisation size can be improved by increasing flexible division of labour, and making more effective use of information technology (Piore \& Sabbel, 1994). Organisational weaknesses may be minimised by changing or enlarging the pool of entrepreneurial talents. At times replacing the chief executive manager may be the solution to organisation inefficiency. Bringing in more members expands the pool of resources, and provides scope for expanding the size of the firm. The expansion of firm size inevitably brings about additional bureaucracy and possibly some loss of control (Williamson, 1985). In Prescott and Visscher (1980) the expansion of the firm, by changing a fixed organisational input that is not easy to replicate, exacerbates the inefficiencies arising from imperfect knowledge. Holstrom (1989: 320) asserts that "to note that bureaucracy is viewed as an organisational disease is equally accurate".

Labour produces goods and services as a team (Alchian \& Demsetz, 1972), although with team production it is difficult to separate the marginal product of each input. Nevertheless, technology is such that efficient production involves teamwork. The management function then requires the monitoring of individual performances to identify slacking and to enforce an appropriate disciplinary system to deal with the slackers. Without proper control of team production, a potential "free rider" problem exists, as an individual worker then has the incentive to shirk. The monitor observes the behaviour and relations between the firm and workers. He has the power to discipline resource owners by terminating their contracts and hiring replacements. All this entails internal organisational costs. But then who monitors the monitor? It is the residual claimant, the "natural person". The firm therefore combines two cost saving mechanisms and one cost raising mechanism. By avoiding market transactions the firm saves on transaction costs.

\section{Transaction Costs}

Transaction costs are defined by Arrow $(1969: 48)$ as "the costs of running the economic system". Douglass North (1994:361) describes transaction costs as "the costs of specifying what is being exchanged and of enforcing the consequent agreements." The building block of transaction costs is the transaction itself, an agreement between two parties. Such costs contain two main elements: information costs and contract costs, i.e. the cost of specifying what is being traded plus the cost of enforcing the contract. Transaction costs can be avoided if economic coordination is undertaken within the firm. 
However, the firm itself would then have to undertake the task of arranging and policing, that would otherwise have been performed by the market. Again costs (management) are involved for the firm which are the equivalent of transaction costs involved in using the market. By taking advantage of specialisation and team cooperation, the firm gains a cost reducing method of production. By having an administrative structure to monitor performance, punish slackers and reward hard workers, the firm's costs increase. But as long as these costs are more than compensated for by cost-effectiveness gains, it pays to create the firm (Coase, 1964). Thus, the firm emerges as a means of economising on transaction costs.

Firms choose to perform activities internally rather than to purchase them in the market, when the costs of monitoring internal efficiency are less than the transaction costs of using markets. From this perspective, firms exist because producing for others, as compared to self-sufficiency, is efficient due to economies of scale, specialised activity and the prevalence of low transaction costs (Demsetz, 1997: 11). In the transaction cost theory, if the transaction costs become lower, activities previously undertaken within firms are then performed in markets. Should transaction costs turn out to be prohibitively high, the market is abandoned in favour of intrafirm allocation of resources. Managed allocation of resources within the firm becomes viable if the cost of coordinating resources through market arrangements (transaction costs) exceeds the cost of managing them within the firm (Coase, 1964).

In the Coasian literature, a firm is viewed as an alternative to the market, as a resource allocating mechanism. In order to minimise transaction costs different types of governance are required for different types of transactions (Williamson, 1975). Transactions for which the market is a highly costly form of governance are withdrawn from market competition and internalised in the firm. In other words, administrative governance supercedes market allocation. The fact that market transactions involve costs does not necessarily imply that all market transacting will be superceded, because firm coordination also entails costs. Depending on the nature of business, replacing market transacting may involve cost saving that is not of a sufficient magnitude to compensate for internal organisational costs. Further, the existence of decreasing returns to the entrepreneurial function will imply that cost savings may decline as the firm expands. Thus, Coase's argument of "substitution on the margin" indicates that the equilibrium of the firm, or the boundary between the firm and the market, is determined by the condition that the marginal cost of firm coordination being equal to the marginal cost of market transaction.

Efficiency in the form of economising on transaction costs is an important cause of the emergence of firms. However, decision-makers often become lax over 
time, especially when there is no proper monitoring, accountability and control. Costs escalate and so-called $x$-inefficiency develops (Leibenstein, 1987). On the governance side, bureaucratic costs increase and there is no organisational innovation, as rigidities and conflicts in labour relations lead to the firm disintegrating vertically. Therefore, the efficient size of the firm is determined where the marginal intrafirm transaction cost equals the market transaction cost (Coase, 1964).

An important question is: what makes transactions costly? Wiliamson (1985) suggests that three transaction characteristics are critical: frequency, uncertainty and asset specificity (as measured by the foregone economic benefits of discontinuing a relationship). Each attribute is claimed to be positively related to the adoption of internal governance.

As asset specificity increases, transaction costs increase too, and so do the potential benefits of vertical integration. When the level of specialised assets is high, each party is more at risk given that he must engage in more and more pre-transaction planning, during the transaction monitoring, and posttransaction enforcement costs that may become prohibitive (Kreps, 1994). Holmstrom and Roberts (1998) argue that higher levels of uncertainty and higher degrees of asset specificity, especially when they occur together, result in a more complex contracting environment and a greater need for adjustment after commitments have been made. Accordingly, a hierarchical relationship, in which one party has formal control over both sides of the transaction, is presumed to be easier in resolving potential disputes than does a market relationship. The frequency of a transaction also matters because the more often it takes place, the more widely spread are the fixed costs of establishing a non-market governance system (Holmstrom and Roberts, 1998).

Williamson (1975: 20) states that "it is always the joining of human with environment factors, not either taken by itself, that poses transactional problems". Opportunism generates rent-seeking behaviour on the part of untrustworthy individuals, pursuing self-interest in deceitful ways. Transactions and exchange then involve costly bargaining and monitoring. A high degree of trust is required if these rents do not result in squabbles. In order to limit the extent of opportunism, firms are likely to integrate (internalise) the transaction, where opportunism is controlled by fiat (Williamson, 1975).

Bounded rationality creates problems (i.e. costs) as individuals' ability to seek optimising solutions to complex problems under uncertainty is limited. Indeed, one party to a transaction may have more information than another, and may not adequately deal with contingencies because it may be costly to anticipate them or include provisions for dealing with them within a contract. After all, no 
contract can spell out every contingency. All complex contracts are then unavoidably incomplete. In these circumstances, internal organisation in the administration of transactions may have advantages over market transacting. In sum, when the interaction of human and environment factors create substantial costs in market exchanges, "internal organisations" (firms) will emerge as an alternative to markets in order to economise on transaction costs.

\section{ORGANISATION WITHIN FIRMS}

For a small firm, even a non-hierarchical, internal structure of planning and authority in the administration of transactions may be efficient. The governance mechanism within the small firm can be made up by peer groups (members who perform similar or integrated tasks within the organisation). The small peer-group organisation has some advantages over the market in certain circumstances, in that each member is firmly committed to the firm, making limited demands on its indivisible assets, thereby lowering unit costs and enhancing associational gains. Monitoring in peer groups is informal. The group can handle the problems of adverse selection and moral hazards, given that it can tightly monitor free-riders and shirkers, and rigorously screen potential members (Williamson, 1985). However, an optimal internal structure does not remain optimal indefinitely. As the firm evolves and its size increases, synergies develop, more complex tasks are tackled, and peer groups are usually replaced by simple hierarchies. As the complexity of business increases further, simple hierarchies may have to be linked up with more sophisticated (multistage) structures and monitoring systems.

Alchian and Demsetz (1972) add that a hierarchical internal structure will evolve in response to market failures, which often occur in the presence of technological non-separability. Co-operative relations in a firm cannot be maintained when opportunism is rampant and trust lacking. It is the crucial role of the organisational leaders to engineer a trusting environment so that both employers and employees act co-operatively rather than opportunistically. The provision of appropriate incentives and efficiency wages (Akerlof \& Yellen, 1986; Gibbons, 1998) as well as the adoption of productivity measurement and enhancement systems may help to generate an efficient internal administrative structure that minimises cost and enhances profit or service delivery (Holmstrom \& Milgrom, 1994). Under stable circumstances, trust engendered by repeated dealing might be a cost-minimising response, favourable to the development of the firm.

The emergence of a relationship of coordination and trust that sustains cooperative arrangements may have a cultural dimension. A strong organisational 
culture which encourages, for example, high degree of moral commitment among the members of a firm will make members more trustworthy. This reduces the need for supervision and lowers transaction costs. A reduction in transaction costs in turn becomes a source of competitive advantage that influences the economic performance of the firm (Peters \& Waterman, 1982; Casson, 1991; Gibbons, 1998). A change in organisational culture is difficult to imitate in the short term. This may evolve over time with the development of the firm (Nelson \& Winter, 1982). In the absence of a strong work ethic, individuals might show little or no personal loyalty to the firm and might 'legitimise' certain behaviour that raises agency costs, making the firm uncompetitive. But firms with a diversified, technical and moral culture encourage pragmatic incremental "tinkering" with both high and low levels entrepreneurship (Casson, 1991). Taking an evolutionary approach to the firm, Nelson and Winter (1982) argue that successful routines will lead a firm to expand into areas where the success can be replicated with new knowledge. Chandler (1992) and Jovanovic (1982) argue that the firm learns and grows with the benefit of experience. Such growth is said to driven much less by the desire to reduce transactions or agency costs, but more by the wish to utilise competitive advantages accumulated through learning processes.

\section{ORGANISATIONAL SICKNESS}

Firms and organisations consist of people, bound together by a common purpose to achieve certain objectives. Douglass North (1994) in his Nobel Memorial Lecture in Economics stated that organisations include political (for instance, political parties or city councils), economic (firms, trade unions, family farms and cooperatives), social (church, clubs and athletic associations) and educational bodies (universities, schools, and vocational training centres). Firms can become sick in much the same way as people do. The sickness of organisations in some ways reflects the behavioural illness of people, especially the key role players and entrepreneurs. People get old, tired, and slow down, usually becoming far less effective than when they were young.

Organisations can become unhealthy through a mismatch of their internal systems and external environment, through competition, legislation, economic conditions and traumatic circumstances. Using a comparison with biology, Marshall thought that not all firms could live forever. They are "organic" entities. Entrepreneurs can identify opportunities, develop strategies, marshall resources, take initiatives and bring a firm into being. They can nourish it to adulthood. Soon enough entrepreneurs die. Succeeding managers are frequently less talented. New firms, fertilized by other, perhaps younger, entrepreneurs tend to emerge and flourish. 
Nature still presses on the private business by limiting the length of the life of the original founders, and by limiting even more narrowly that part of their lives in which their faculties retain full vigour. And so, after a while, the guidance of the business falls into hands of people with less energy and less creative genius, if not with less active interest in its prosperity (Marshall, 1961: 316).

Marshall examined the life-cycle of the firm by comparing it to trees in a forest. As saplings the trees compete for light and air against their larger neighbours and many stagnate, fail to develop and die. Some small trees would however eventually grow and replace the larger trees, with the forest constantly evolving and changing. The more successful ones grow rapidly until they dominate the environment. Their years of domination are, however, numbered, and the trees eventually lose vitality and are replaced by younger and more vigorous ones. The analogy may be applied to business firms. For the existing firms, organisational death may happen through failures, acquisitions and mergers. The exit rate may be particularly high for small and young small firms with limited resources.

Unlike the neoclassical theory, the firm is not a "black box". It operates in the real world of imperfect information. The firm needs information about the existence and attributes of rival products, and the main factors influencing actual and potential demand. The neoclassical result of perfectly healthy firms might only be obtained if transactions were costless. But in reality it is costly to transact business. Decision makers have to search for the necessary information themselves. Individuals' ability to handle complex information is limited. Thus, information asymmetry (impacted information), bounded rationality and uncertainty, all mean that the perfectly efficient firm of the traditional theory is almost non-existent. However, in the real world, there are many firms that are efficient, fit and healthy. They exist to achieve objectives, and their entrepreneurs and chief executive officers, as top decision-makers, are determined to remain healthy to meet the continuing realities and challenges of the environment. The market is in a state of continuous change, and this brings about various opportunities and threats. Firms that cannot meet the challenges of changing market conditions, or are too slow to adapt to changes, are likely to be overtaken by their more dynamic competitors, and might not survive in the long run. For organisations to keep their heads in the sand, not sensing the "atmospheric characteristics", both internal and external, is a sure way to illhealth and eventual demise.

Keeping up with internal and external pressures is the key element to organisational survival. Survival and fitness depend on the adaptability of the firm and its ability to match its strategy to a changing world. This certainly requires a pattern of behaviour among the internal resources, input suppliers and 
entrepreneurs that is congruent with the overall mission of the firm. Of central importance to the continued health of the firm is the quality of its leadership and entrepreneurship, or what Penrose (1995) described as managerial and entrepreneurial versatility.

Organisations that face little competition can get fat, sluggish, lazy, and selfindulgent. This may be a symptom of a malady. The solution should be prevention, not to wait for a crisis to apply the cure. Most markets are contestable in modern times (Baumol, 1982). The market does not tolerate laziness. Success achieved today, even through a degree of monopoly power, is no guarantee of success tomorrow. In this turbulent "information age", domestic and external competition imply that firms must take decisions fast. They must be flexible and responsive to customers, prepared to anticipate threats and opportunities, and consistently improve the quality of products and processes. Competition should induce organisations to learn how to survive. Learning entails developing a structure by which to interpret the signals received by the senses (North, 1994).

In the long run, survival depends on developing superior core competencies in the niche fields in which the firm operates. To maintain success, the firm has to remain pro-active, always put the customer first and be innovative. Any existing organisation goes down fast if it does not innovate. Firms that fail to meet the changing needs of their consumers in a creative and cost-effective manner will not survive, because customers will go elsewhere. Excellent customer service should be the guiding principle of the firm's operation; ultimately the consumer is sovereign. The sign of a healthy business is a satisfied customer. As Drucker (1992: 230) puts it "the single most important thing to remember about any enterprise is that results exist only on the outside. .... Inside an enterprise, there are only costs."

\section{Some Characteristics of Unhealthy Organisations}

1 There is a lack of fit between the firm's products and its market environment, or a poor "match quality" between the firm and its managers.

2 There is little personal commitment and investment in organisational objectives, except at top management level. "Without such commitment, there is no enterprise, there is only a mob" (Drucker, 1992: 229). The public expect prompt and efficient service delivery from workers or civil servants, but the latter attribute weaknesses to failures of service delivery management. Management often blame workers for a lack of respect or commitment that is not in the workers' own career interests. The 
organisational objectives then range, or perhaps drift, from the "official" goals to those of institutional practice.

3 There is a conflict of interest between the principals and agents (side agency theory). People are interested in receiving income with consumption on the job, in shirking and excessive risk aversion. Costs escalate as more units are hired, partly because of resistance, militant union action and inflexible labour legislation. Real costs of the firm escalate as there might be little scope for utilizing labour-saving technical progress (Baumol's cost disease).

4 Individuals in the firm perceive that things are going wrong. But they do not care to do anything about the problems, possibly because of wrongly perceived self-interest, until the firm becomes subject to some form of external investigation.

5 Management tries to get things done. But there is a lack of adequate communication or wrong information is transmitted. Departments are starved of resources. Out of individuals' greed and jealousy, decisions that have to go through the middle management filter, tend to be bottlenecked or sabotaged. Decisions are made with inadequate information or advice, giving rise to opportunism.

6 There is a lack of transparency. Mistakes and problems are not handled in an effective way. Orders, policies and procedures are not followed. Individuals may be learning but the organisation is not.

7 People resist change when there is a need to cooperate and innovate. The organisation is too bureaucratic and slow to act.

8 Systems of control and discipline become porous and almost defunct. Incentives and opportunities exist for contractual non-performance.

9 For certain operations, market transactions are bypassed in favour of inhouse activities even though market transactions may be more costeffective and efficient than internalisation (bounded rationality and rentseeking).

10 There is a lack of team spirit in planning, controlling, leading, evaluating, organising and decision-making.

11 Rigorous financial, customer-focused and other performance criteria are not applied. 
A private firm will not survive if its activities do not generate enough revenue to cover its costs. A non-profit organisation, however, may somehow survive in the short term through external funding, possibly from the public sector or outside donor agencies. Even NGOs are now under pressure to account for their continued viability, in terms of cost effectiveness and maximum delivered value to customer or community service in a transparent manner. As major sources of funding dry up, and as actual and potential customers desert the firm for its innovative competitors' products, the outlook for the continued existence of the organisation becomes bleak. In the absence of "surgery", the firm goes through an inert or slack phase (Leibenstein, 1987) before meeting its eventual demise in the long run, through either closure or merger/acquisition. However, the occurrence of a catalytic event provides scope for alert entrepreneurs to seize market gaps and spring into action, through refining the efficiency and effectiveness of existing organisations and creating new organisations.

\section{TREATMENT}

As with individuals, firms have to live in and adapt to a rapidly changing environment. Like people, organisations have to think how they can remain on the pathway of a healthy existence. Various symptoms of illness have to be analysed within a diagnostic framework before any therapy can be applied to a firm, to be healthy and successful.

As purposeful institutions, all firms have certain objectives to achieve, underpinned by mission statements and strategies. All these function through people. Skillful use of strategic planning and control is vital for a healthy enterprise. Sanctions or punishment should exist for irresponsible managerial behaviour. As every organisation is different; there might not be a common cure for each organisational problem. However, the nature of the sickness would determine the type of remedies to be applied.

Information is required to decide whether or not a firm is functioning well. In this regard, there should be trust and communication among different units of the firm so that all role players can keep in touch with what is going on in the firm and around it. Members should understand and appreciate the operational and strategic thinking underlying the short and long term goals of the firm. Financial criteria (such as profits, rate of retum on investment, cash flows, growth of sales revenue), socio-economic targets (age of the firm, community involvement, social responsibility, average cost, employment and output growth), and behavioural norms (strikes, labour turnover, job satisfaction and morale) should represent the pulse of a firm. 
The organisation has to unleash entrepreneurship and nourish an entrepreneurial culture at all levels within it. This requires management's commitment to invest in new technologies and human capital, to equip their employees with the necessary knowledge and analytical skills (bottom-up empowerment and collective learning), to improvise genuine self-renewal, without neglecting improvements to the efficient delivery of existing product offerings. Organisational learning is an essential component of entrepreneurial selfrenewal. Self-renewal is essential for tomorrow. Accordingly, the firm has to fine-tune existing products and seek opportunities for new product developments in line with its core competencies. Furthermore, it has to seek new ways of adding value and creating additional satisfaction for customers, to adapt more effectively to the changing environment. The firm has to match external opportunities to internal resources. What makes the difference between survival and extinction, is the ability of a firm to vary its responses to the market (McCrimmon, 1995).

Entrepreneurs and the management are responsible for the condition of health of their organisations. They need to constantly exercise pro-active measures, new ideas, risk taking, experimentation, feedback and adaptation on the basis of what succeeds or fails in the market. The firm needs a structure that sustains organisation development. In such an environment, employees are to be motivated to think and act as entrepreneurs. Management should offer incentive structures and a value system that encourage individuals to make a wholehearted response to customer needs (Gibbons, 1998). Trustworthy relationships should be built between employees and managers. When leaders provide opportunities for people to express their potential at work, organisations become productive and healthy. Productivity is a means to health for most people and organisations (Hall and Maritz, 1997). In addition, the firm should build on its strengths and develop strategic networks that reflect market orientation.

Adequate finance is a necessary but not sufficient condition for the continued health of an enterprise, especially small firms. As Marshall states (1961: 311) "ability always finds the necessary capital"; and Penrose (1995: 39) adds that " there is a relation between entrepreneurial ability and the finance a firm can attract". The achievement motivation (n-Ach) level of individuals are equally vital for enhanced enterprise effectiveness and economic prosperity (McClelland, 1961). McClelland associates high n-Ach with personal effort, responsibility for solving problems and attaining goals, seeking concrete feedback on and information how to improve performance, capacity to plan ahead and be aware of the passage of time, and interest in excellence for its own sake. The n-Ach levels of subjects can be aroused or augmented by appropriate training. Individuals should be exposed to specific training in $\mathrm{n}-\mathrm{Ach}$, for it 
impacts significantly on enhanced entrepreneurial effectiveness and organisational performance (Boschoff and Boer, 1998).

\section{CONCLUSION}

The emergence of firms and different organisational structures are underpinned by efficiency considerations, in the form of Coasian transaction costs economising. The resultant internal structures may change from simple governance to hierarchies as firms' activities become more complex. Firms are formed by entrepreneurs and people. Organisations can become sick, just as people do. Different firms may show different symptoms and might be afflicted by different ills. The behavioural sicknesses of firms may reflect the behavioural illnesses of people. The quality of entrepreneurship and management as well as the productivity of the work force are critical elements supporting an organisation's health.

A thorough diagnostic framework is, therefore, required to study various "symptoms" and prescribe appropriate treatment to enable a firm to cure its ills and hopefully bring about a healthy, productive and effective organisation. The future belongs to healthy firms. They are the organisations with strategies and resources that optimally fit the environment, adapt and respond quickly to change, and reinvent themselves rapidly to exploit opportunities. Healthy firms are better tuned to delivering value to present and future customers.

\section{REFERENCES}

1 AKERLOF, G. A. \& YELLEN, J. L. (eds.) (1986) Efficiency Wage Models of the Labour Market, Cambridge University Press, Cambridge.

2 ALCHIAN, A. \& DEMSETZ, H. (1972) "Production, Information Costs and Economic Organisation", American Economic Review, 62: 777-95.

3 ARROW, K.J. (1969) 'The Organisation of Economic Activity', in The Analysis and Evaluation of Public Expenditure: The PPB System, Joint Economic Committee, Washington, DC.

4 BAUMOL, W.J. (1982) "Contestable Markets", American Economic Review, 72: 1-15.

5 BOSCHOFF, A.B. \& BOER, J.H. (1988) "N-Ach Training, Organizational Climate and Organizational Performance", Development Southern Africa, 5(1): 73-87.

6 CASSON, M. (1991) The Economics of Business Culture: Game Theory, Transactions Costs, and Economic Performance, Clarendon Press, Oxford. 
7 CHANDLER, A.D. (1992) "Organisational Capabilities and the Economic History of the Industrial Enterprise", Journal of Economic Perspectives, 6 (3): 79-100.

8 COASE, R. (1964) "The Nature of the Firm", Economica, 1937, 386-405, reprinted in Readings in Price Theory, The American Economic Association, Allen and Unwin, New York: 331-51.

9 DEMSETZ, H. (1997) The Economics of the Business Firm, Cambridge University Press, Cambridge.

10 DRUCKER, P.F. (1992) The New Realitie, New York, Harper and Row.

11 GIBBONS, R. (1998) "Incentives in Organizations", Journal of Economic Perspectives, 12 (4): 115-32.

12 HALL, J. and MARITZ, F. (1997) "Leadership: Turning Potential into Productivity", Management Today, July: 27-31.

13 HOLMSTROM, B. and MILGROM, P. (1994) "The Firm as an Incentive System", American Economic Review, 84 (4): 972-91.

14 HOLMSTROM, B. and ROBERTS, J. (1998) "The Boundaries of the Firn Revisited", Journal of Economic Perspectives, 12 (4): 73-94.

15 JOVANOVIC, B. (1982) Selection and the Evolution of Industry. Econometrica, 50(4): 649-70.

16 KREPS, D.M. (1994): A Course in Microeconomic Theory, Harvester Wheatsheaf, London.

17 LEIBENSTEIN, H. (1987a) "X-inefficiency Xists - Reply to an Exorcist", American Economic Review, 68: 203.

18 LEIBENSTEIN, H. (1987) Inside the Firm: The Inefficiencies of Hierarchy, Cambridge University Press, Mass.

19 LUCAS, R.E. (1978) "On the Size Distribution of Business Firms", Bell Journal of Economics, 9: 508-23.

20 MARSHALL, A. (1961) Principles of Economics, 8th ed., Macmillan, New York.

21 McCLELLAND, D. C. (1961) The Achieving Society, Van Nostrand, New York.

22 NELSON, R.L. and WINTER, S.G (1982) An Evolutionary Theory of Economic Change, Harvard University Press, Mass.

23 NORTH, D. (1990a) Institutions, Institutional Change and Economic Performanc, Cambridge University Press, Cambridge.

24 NORTH, D. (1994) "Economic Performance Through Time", The American Economic Review, June, 359-68.

25 PENROSE, E. (1995) The Theory of the Growth of the Firm, Oxford University Press, Oxford.

26 PETERS, T.J. and WATERMAN, R. H. (1982) In Search of Excellence, Harper and Row, New York.

27 PETERS, T. (1987) Thriving on Chaos, Alfred A Knopf, New York. 
28 PIORE, M and SABBEL, C. (1984) The Second Industrial Divide: Prospects for Prosperity, Basic Books, New York.

29 RICKETTS, M. (1994) The Economics of Business Enterprise, Harvester Wheatsheaf, London.

30 WIILIAMSON. O. (1975) Markets and Hierarchies: Analysis and Antitrust Implications: A Study in the Economics of Internal Organisation, Free Press, New York.

31 WILLIAMSON, O. (1985) The Economic Institutions of Capitalism: Firms, Markets Relational Contracting, Collier Macmillan, London. 